\title{
Reducing ability of infusions from waste of spicy- aromatic raw materials in the technology of alcoholic beverages
}

\section{Oleg Kuzmin ${ }^{1}$, Volodymyr Isaienko ${ }^{2}$, Irina Koretska ${ }^{1}$, Djamal Rakhmetov ${ }^{3}$, Viktor Goots ${ }^{\mathbf{4}}$, Svitlana Oliynyk ${ }^{\mathbf{1}}$}

\author{
1 - National University of Food Technologies, Kyiv, Ukraine \\ 2 - National Aviation University, Kyiv, Ukraine \\ 3 - M. M. Gryshko National Botanic Garden of NAN of Ukraine, Kyiv, Ukraine \\ 4 - Kyiv National University of Culture and Arts, Kyiv, Ukraine
}

Keywords:

Spicy-aromatic

Waste

Alcoholic

Beverage

Antioxidant

Redox

Infusion

\section{Article history:}

Received 16.02.2020

Received in revised

form 29.03.2020

Accepted

30.06.2020

\section{Corresponding}

author:

Oleg Kuzmin

E-mail:

kuzmin_ovl@ukr.net

\section{DOI:}

$10.24263 / 2310-$

1008-2020-8-1-3

\section{Abstract}

Introduction. The aim of the research is to study the reducing ability of aqueous-alcoholic infusions from waste of aromatic raw materials in the technology of alcoholic beverages.

Materials and methods. The regenerative ability of infusions from waste of aromatic raw materials: Perilla frutescens; Elsholtzia stauntonii Benth; Artemisia abrotanum; Monarda didyma; Agastache foeniculum; Satureja hortensis; Ruta graveolens; Nepeta transcaucasica Grossch was determined by the method of redoxmetry and $\mathrm{pH}$-metry; sensory indicators - according to the expert method.

Results and discussion. Waste plant spice-aromatic raw materials, which are formed after maceration, during further preparation, can be reused in the technology of alcoholic beverages.

In relation to the control ( $7.80 \mathrm{pH}$ units) infusions have a $\mathrm{pH}$ value of 6.73 units $p H$ (Agastache foeniculum) up to 7.35 units $p H$ (Satureja hortensis), which is $13.72 \%$ and $5.77 \%$, respectively, less than control. The value of the minimum theoretical redox potential for aqueousalcoholic infusions $E h_{\text {min }}$ from $219.0 \mathrm{mV}$ (Satureja hortensis) to 256.2 $\mathrm{mV}$ (Agastache foeniculum), which is $14.06 \%$ and $33.44 \%$ more than in the control $\left(E h_{\min } 192 \mathrm{mV}\right)$. The value of the actually measured redox potential for aqueous-alcoholic infusions $E h_{\text {act }}$ from $94.0 \mathrm{mV}$ (Monarda didyma) to $141.0 \mathrm{mV}$ (Ruta graveolens), which is more than $2.17 \%$ and $53.26 \%$, respectively, for the control $\left(E h_{\text {act }} 92 \mathrm{mV}\right)$.

Aqueous-alcoholic infusions from wastes of spicy-aromatic raw materials have a reduction capacity (reduction energy $-R E$ ) from 101.4 $\mathrm{mV}$ (Ruta graveolens) to $153.2 \mathrm{mV}$ (Monarda didyma), which is greater than the control (aqueous-alcoholic mixture) $R E 100 \mathrm{mV}$ by $1.40 \%$ and $53.20 \%$ respectively.

Aqueous-alcoholic infusions from waste of spicy-aromatic raw materials have the value of S.e. from 9.47 to 9.68 points in relation to control S.e. 9.21 points. The highest value of S.e. 9.68 points are characteristic of the aqueous-alcoholic infusion of Agastache foeniculum: color - light amber (1.98 points); taste - bright ethereal, herbal, fragrant (3.98 points); aroma - bitter-sour, tart (3.72 points).

Conclusion. The use of waste from the aromatic raw materials of Monarda didyma in aqueous alcoholic tinctures leads to an increase in the reducing characteristics of $R E$ infusions by $53.20 \%$, and positive sensory indicators of S.e. -9.51 points on a 10 -point scale. 


\section{Introduction}

Waste reduction is a key challenge for the sustainable development of the food industry (Barik, 2019; Tekler et al., 2019; Martin-Rios et al., 2018) [1-3], so reducing it is a pressing issue for most businesses in the industry (Hall, Howe, 2012; Fujii, Kondo, 2018) [4, 5]. Waste recycling and utilization is a strategic goal for each company (Fujii, Kondo, 2018; Galanakis, 2020; Garcia-Garcia, 2019) [5-7], which involves the involvement of innovative technologies based on the evaluation of decisions in reducing the cost of finished products, minimizing raw material losses, increasing the yield of finished products (Tekler et al., 2019) [2]. The practical implementation of innovative measures allows to establish relationships between processes and technologies of food industry processing and provides an opportunity to form the main provisions in the field of waste management (Mo et al., 2018) [8].

Today, for the production of alcoholic beverages, a certain amount of plant raw materials is used, which forms waste. Currently, the use of vegetable raw materials in the technology of alcoholic beverages is very relevant (Andreou et al, 2018; Chandrasekara, Shahidi, 2018; Iannitti, Palmieri, 2009; Kawa-Rygielska et al, 2019) [9-12]. Of particular interest in the production of alcoholic beverages is a spicy-aromatic raw material that exhibits antioxidant and tonic properties (Vergun et al, 2019) [13]. At present, the antioxidant characteristics of all prescription components, food additives, biologically active substances and their combinations have not been sufficiently studied (Buglass et al, 2012; Grunert et al, 2018; Gulua et al, 2018) [14-16].

In the process of extracting or infusing spicy-aromatic raw materials with an aqueousalcoholic mixture, waste remains, which can be further processed and reused. Spice-aromatic plants can be considered a promising raw material for the production of alcoholic beverages: Perilla frutescens, Elsholtzia stauntonii Benth, Artemisia abrotanum, Monarda didyma, Agastache foeniculum, Satureja hortensis, Ruta graveolens, Nepeta transcaucasica Grossch, due to their positive characteristics.

Perilla frutescens. Perilla frutescens is rich in natural compounds that could be developed as nutraceuticals (Ahmed, Tavaszi-Sarosi, 2019; Lee et al., 2017; Igarashi, Miyazaki, 2013) [17-19] and/or phytomedicine (Ahmed, Tavaszi-Sarosi, 2019) [17]. More 100 compounds have been reported for Perilla frutescens and most of them are contributed to its medical benefits (Ahmed, Tavaszi-Sarosi, 2019; Lee et al., 2017; Yu et al., 2017; Lee et al., 1997; Liu et al., 2000) [17, 18, 20-22] such as anti-allergic, anti-inflammatory, antioxidant (Ahmed, Tavaszi-Sarosi, 2019; Lee et al., 2017; Yu et al., 2017) [17, 18, 20], anticancer, anti-microbial, anti-depressive and anti-cough effects (Yu et al., 2017; Lee et al., 1997; Liu et al., 2000) [20-22]. The health beneficial capacities of Perilla frutescens are related to its metabolite contents (phenolic acids, monoterpenes, flavonoids, and triterpenoids (Banno et al., 2004; Lee et al., 2013; Asif, 2012; You et al., 2014), [23-26]. Perilla frutescens characterized with the predominance of perillaldehyde, perilla ketone, $\beta$-dehydro-elsholtzia ketone, limonene, shisofuran, farnesene $(\mathrm{Z}, \mathrm{E}, \alpha), \beta$-caryophyllene, trans-shisool (Ahmed, Tavaszi-Sarosi, 2019) [17].

Elsholtzia stauntonii Benth. Plants of the genus Elsholtzia stauntonii Benth have a long history of medicinal use in folk. The phytochemical investigations revealed the presence of flavonoids, phenylpropanoids, terpenoids, and other compounds. Abundant volatile components are also identified (Guo et al., 2012) [27]. As folk medicine, the plants in the genus have been used for the treatment of colds, headaches, pharyngitis, fever, diarrhea, digestion disorder, rheumatic arthritis, nephritises, and nyctalopia in China (Guo et al., 2012; Wu et al., 1977) [27, 28]. 
Artemisia abrotanum. Artemisia abrotanum is a rich source of active biological compounds that include terpenoids, sesquiterpenoids, flavonoids, and coumarins (Afshar et al., 2017; Bora, Sharma, 2011; Tan et al., 1998; Taleghani et al., 2020) [29-32]. Artemisia abrotanum, a common plant used in the culinary and cosmetics industries, has been reported to accumulate high levels of triquinane silphiperfol-5-en-3-one A (Muangphrom et al., 2019) [33]. Artemisia abrotanum and its active phytochemicals have been introduced as having antimalarial, antioxidant, cytotoxic, antispasmodic, anthelmintic, neuroprotective, antiinflammatory, and antimicrobial agents (Taleghani et al., 2020; Amirmohammadi et al., 2014) [32, 34].

Monarda didyma. Twenty-nine constituents found in the green tissue samples of Monarda didyma turn out to be mainly terpenoids with linalool, p-cymene, thymol and thymol methyl ether as main compounds (Wryblewska et al., 2019) [35]. The different chemical composition was represented by the flowers essential oil which possesses p-cymene and terpinolene (above 80\%) as main compounds (Wryblewska et al., 2019) [35]. Monarda didyma oil revealed the strong antimicrobial activity and completely inhibited the growth of Candida albicans yeast as well as Bacillus cereus and Pseudomonas fluorescens bacteria in a concentration of $0.01 \%$ (Wryblewska et al., 2019) [35]. Monarda plants contained of biologically active thymoquinone (Sovova et al., 2015) [36].

Agastache foeniculum. Agastache foeniculum is a perennial aromatic plant with antimicrobial and antifungal properties and useful for gastrointestinal problems. Components were identified, representing $95.4 \%$ of the oils including methyl chavicol, limonene, spathulenol and caryophyllene oxide (Hashemi et al., 2017) [37]. The extracts of flowers and leaves of Agastache foeniculum exhibited a high content of flavonoids, antioxidants and phenolic compounds (Shtereva et al., 2016) [38]. Analysis confirmed the presence of phenylpropanoids i.e., rosmarinic acid, tilianin, and acacetin (Park et al., 2014) [39].

Satureja hortensis. Satureja hortensis has been also used as folk remedies to treat various ailments such as cramps, muscle pains, nausea, indigestion, diarrhea, and infectious diseases. It has showed antispasmodic, anti-diarrhoeal, antioxidant, sedative as well as antimicrobial properties (Deans, Svoboda, 1989; Hajhashemi et al., 2000; Leung, Foster, 1996; Madsen et al., 1996) [40-43]. Satureja hortensis may be a valuable source of dietary and pharmacologically important phenolic compounds, especially rosmarinic acid, in pharmaceutical and functional food formulations in order to maintain normal health conditions or as a remedy in various diseases caused by oxidative damage (Boroja et al., 2018) [44].

Ruta graveolens. Ruta graveolens possess a wide range of pharmacological activities (Colucci-D’Amato, Cimaglia, 2020) [45] including antioxidant, insect repellent, larvicidal, antimicrobial, antiandrogenic, antidepressant, antihyperglycemic, antihyperlipedimic, antiinflammatory, antitumour and cytotoxic activity on human cancer cell lines (Ahmed et al., 2010; Khouri et al., 2005; Tabanca et al., 2012; Ratheesh et al., 2013; Attia et al., 2018) [4650], antiseptic, stimulant, abortifacient, antirheumatic, anthelmintic, antispasmodic, antiepileptic (Ahmed et al., 2010; Attia et al., 2018; Stashenko et al., 2000) [46, 50, 51]. The phytochemical studies have attributed these biological activities to the presence of some metabolites such as alkaloids, coumarins, flavonoids, ketones and terpenoids (Ratheesh et al., 2013; Attia et al., 2018; Stashenko et al., 2000) [49-51]. Among all the components of the plant extract, rutin - which is highly, if not the most, abundant - positively interacts with the neurophysiology (Colucci-D’Amato, Cimaglia, 2020) [45].

Nepeta transcaucasica Grossch. Nepeta transcaucasica Grossch are widely used in traditional medicine as antimicrobial, antioxidant, antiinflammatory, sedative, relaxant, cholesterol lowering, antiasthmatic, carminative, diuretic, diaphoretic, febrifuge, vermifuge, 
herbicidal, insecticidal and insect repellent, all of them directly related to the specific chemical composition (Salehi et al., 2018) [52]. The active constituents from Nepeta genus may provide the opportunity for the production of antidepressive, antidiabetes, analgestic, anti-inflammatory, lipid-lowering and cardioprotective drugs (Salehi et al., 2018) [52].

These circumstances determine the relevance of this work, which is to develop aqueousalcoholic infusions of vegetable raw materials in the technology of alcoholic beverages.

The aim of the research is to study the reducing ability of aqueous-alcoholic infusions from waste of aromatic raw materials in the technology of alcoholic beverages.

When achieving this goal, it is necessary to solve the following problems:

- To substantiate the prospect of using aqueous-alcoholic infusions from waste of aromatic raw materials in the production of alcoholic beverages;

- To establish the value of the restorative capacity of aqueous-alcoholic infusions from waste of aromatic raw materials;

- Identify the most promising sources of natural antioxidants for use in alcoholic beverage technology.

\section{Materials and methods}

\section{Materials}

The study used plant raw materials that are allowed to be used in the production of alcoholic beverages. In the M.M. Gryshko National Botanic Garden of NAS of Ukraine was created new cultures of spicy-aromatic plants, which became the subject of these studies (Rakhmetov, 2011) [53].

In the Figure 1 shows a photo of aqueous-alcoholic infusions from waste of aromatic raw materials. For preparation of aqueous-alcoholic infusions used the following basic raw materials: ethanol rectified, water, cardboard filtering.

The aqueous-alcoholic infusions should meet the requirements on sensory evaluation: appearance - transparent without sediment and foreign impurities fluid, acceptable opalescence that disappears after filtration; color, taste, aroma - the inherent vegetable raw materials from which they are made, without the foreign taste and odor.

The aqueous-alcoholic infusions must meet the requirements by physicochemical parameters: ethyl alcohol by volume $-20.0-90.0 \%$; mass fraction of essential oil $-0.0-15.0$ $\%$; mass concentration of the total extract $-0.1-20.0 \mathrm{~g} / 100 \mathrm{~cm}^{3}$.

Aqueous-alcoholic infusion - semi-finished product, which is prepared by extraction of raw materials in aqueous-alcoholic solution with a strength of $40 \%$. The static method of extraction is called maceration. The tested aromatic raw material (dry) was infused in a aqueous-alcoholic mixture in this work. 


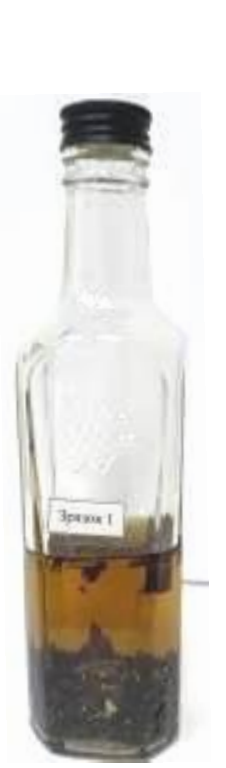

a

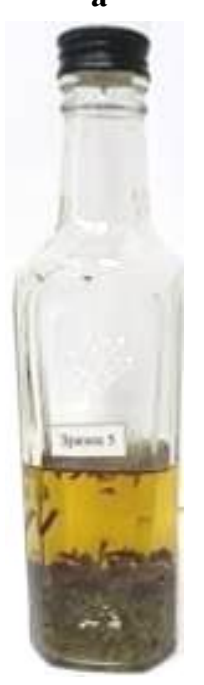

e
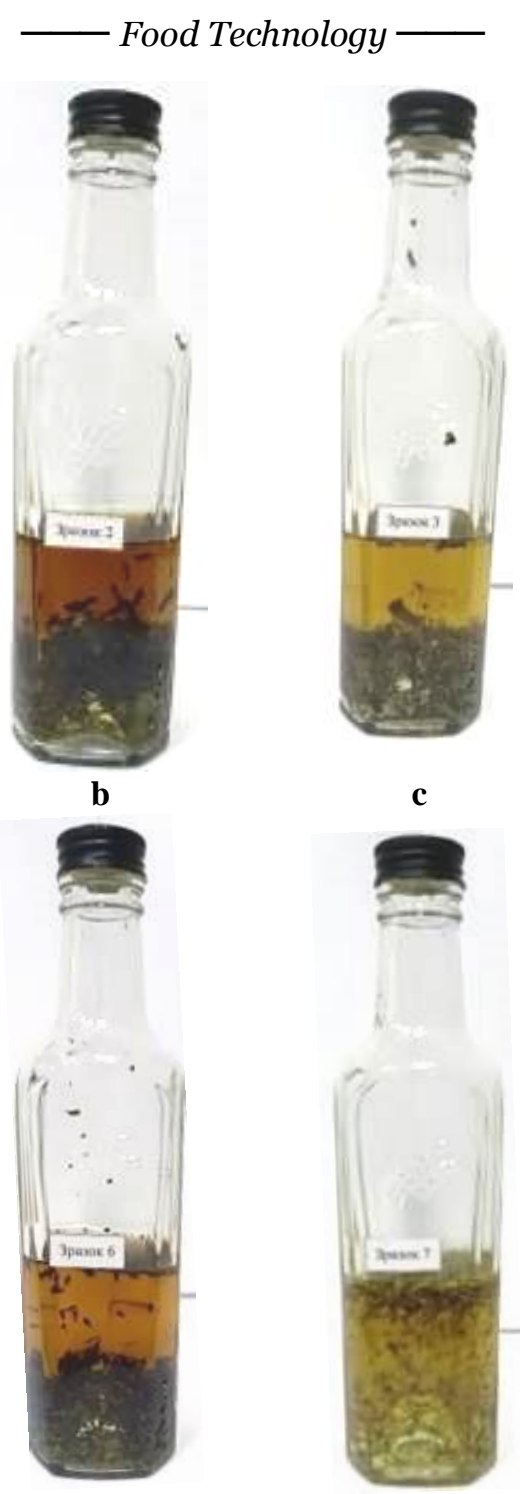

f

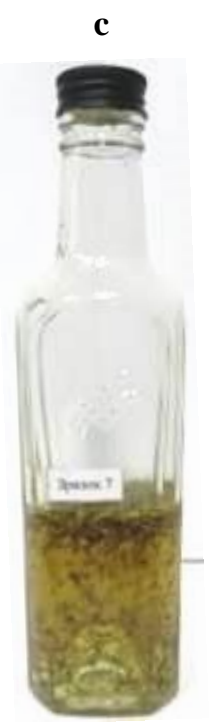

g
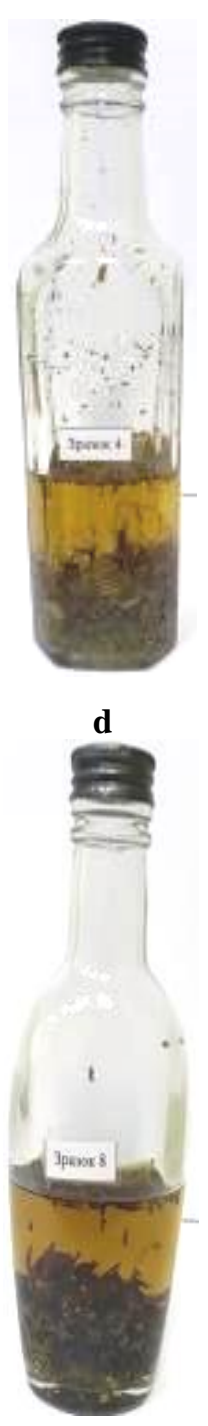

h

Figure 1. Photo of Samples of crushed plant raw materials:

$\mathrm{a}$ - Perilla frutescens; $\mathrm{b}$ - Elsholtzia stauntonii Benth; $\mathrm{c}-$ Artemisia abrotanum;

$\mathrm{d}$-Monarda didyma; $\mathrm{e}$-Agastache foeniculum; $\mathrm{f}$ - Satureja hortensis; $\mathrm{g}$ - Ruta graveolens; $\mathrm{h}$ - Nepeta transcaucasica Grossch.

\section{Description of research procedure}

The first stage - the preparation of infusions. Plant raw materials were minced into a size of $3 \times 3 \mathrm{~mm}$, suspensions of $4 \mathrm{~g}$ were placed into the glass bottles, were filled by $100 \mathrm{ml}$ of alcohol solvent with volume fraction of rectified ethyl alcohol $40 \%$. The resulting infusions were cooled to $20^{\circ} \mathrm{C}$ for 7 days, stirring periodically. 
Next, the infusions were filtered and studies were performed to determine the indicators of active acidity, which was measured on a $\mathrm{pH}$ meter in the mode of $\mathrm{pH}$ measurement with a combined glass electrode. The redox potential was measured in the potential measurement mode with a combined redoxmetric platinum electrode.

\section{Methods of sensory evaluation and antioxidant capacity}

The expert method of determination of values of indexes of quality is based on the account of opinions of group highly skilled specialists-experts. (The expert of - it a specialist on the certain type of object which owns the increased sensitiveness to properties of this object) (Kuzmin et al, 2016; Kuzmin et al, 2017; Kuzmin et al, 2020) [54-56].

To evaluate the antioxidant properties of the obtained aqueous-alcoholic infusions, the method (Priluckij, 1997) [57], based on the difference of redox potential in inactivated inorganic solutions and biochemical complex. The main criteria of this method were its clarity, simplicity, specificity, reproducibility of results and efficiency. A number of researchers also emphasize that method allows to determine the total antioxidant activity of liquid products, including in total in a complex mixture, and multifunctional antioxidants (Kuzmin et al., 2016; Frolova et al., 2019; Kuzmin, 2017) [54, 58, 59].

Formula (1) holds for inactivated inorganic solutions in equilibrium. This formula links the active acidity of the $p H$ and the redox potential (Priluckij, 1997) [57]:

$$
E h_{\text {min }}=660-60 \cdot p H, \mathrm{mV}
$$

where $E h_{\min }$ - minimal theoretically expected value of the redox potential;

$p H-$ active acidity of the test solution.

Acquired redox potential values were compared with actual measurements of $E h_{\text {act }}$ solution. The change of the redox potential toward the recovery energy $(R E)$ was determined by the formula:

$$
R E=E h_{\text {min }}-E h_{a c t}, \mathrm{mV}
$$

where $R E$ - shift of redox potential to the side of recovered meanings (resilence);

$E h_{a c t}-$ actual measured redox potential.

\section{Results and discussions}

\section{Sensory evaluation}

The results of sensory evaluation (Kuzmin et al, 2017) [55] of the obtained infusions on the extractant are presented in the Table 1-2 and Figures 2-3. 
Sensory evaluation (S.e.) of aqueous-alcoholic infusions

\begin{tabular}{|c|c|c|c|}
\hline Plant raw materials & Color & Aroma & Test \\
\hline 1. Perilla frutescens & Light amber & Floral & $\begin{array}{c}\text { Sour-bitter, tart, } \\
\text { unpleasant }\end{array}$ \\
\hline 2. Elsholtzia stauntonii Benth & Light brown & Grassy, floral & Sour-bitter \\
\hline 3. Artemisia abrotanum & Thatched & Grassy & $\begin{array}{c}\text { Bitter, with a long, bitter } \\
\text { aftertaste }\end{array}$ \\
\hline 4. Monarda didyma & Thatched & Fragrant, floral & $\begin{array}{c}\text { Sour-bitter, unpleasant, } \\
\text { with a bitter aftertaste }\end{array}$ \\
\hline 5. Agastache foeniculum & Light amber & $\begin{array}{c}\text { Bright ethereal, } \\
\text { herbal, fragrant }\end{array}$ & Bitter, tart \\
\hline 6. Satureja hortensis & Light brown & $\begin{array}{c}\text { Spicy, fragrant, } \\
\text { herbal }\end{array}$ & $\begin{array}{c}\text { Moderately hot, irritable, } \\
\text { with a sweet taste }\end{array}$ \\
\hline 7. Ruta graveolens & Thatched & $\begin{array}{c}\text { Fragrant, } \\
\text { grassy, floral }\end{array}$ & Bitter, tart \\
\hline $\begin{array}{c}\text { 8. Nepeta transcaucasica } \\
\text { Grossch }\end{array}$ & Light brown & Mint & Soft, pleasant, sweet \\
\hline $\begin{array}{l}\text { 9. Extractant - aqueous- } \\
\text { alcoholic mixture }\end{array}$ & Transparent & Alcoholly & Abrupt \\
\hline
\end{tabular}

Table 2

Sensory evaluation (S.e.) of aqueous-alcoholic infusions

\begin{tabular}{|c|c|c|c|c|c|c|}
\hline Plant raw materials & $\begin{array}{c}\text { Color, } \\
\text { points }\end{array}$ & $\begin{array}{c}\text { Aroma, } \\
\text { points }\end{array}$ & $\begin{array}{c}\text { Flavor, } \\
\text { points }\end{array}$ & $\begin{array}{c}\text { S.e., } \\
\text { points }\end{array}$ & $\begin{array}{c}+/-, \\
\text { points }\end{array}$ & $\begin{array}{c}+/-, \\
\%\end{array}$ \\
\hline 1. Perilla frutescens & 1.95 & 3.65 & 3.87 & 9.47 & 0.26 & 2.82 \\
\hline 2. Elsholtzia stauntonii Benth & 1.89 & 3.80 & 3.93 & 9.62 & 0.41 & 4.45 \\
\hline 3. Artemisia abrotanum & 1.91 & 3.69 & 3.90 & 9.50 & 0.29 & 3.15 \\
\hline 4. Monarda didyma & 1.88 & 3.71 & 3.92 & 9.51 & 0.30 & 3.26 \\
\hline 5. Agastache foeniculum & 1.98 & 3.72 & 3.98 & 9.68 & 0.47 & 5.10 \\
\hline 6. Satureja hortensis & 1.85 & 3.86 & 3.93 & 9.64 & 0.43 & 4.67 \\
\hline 7. Ruta graveolens & 1.91 & 3.70 & 3.95 & 9.56 & 0.35 & 3.80 \\
\hline $\begin{array}{l}\text { 9. Extractant - aqueous-alcoholic } \\
\text { mixture }\end{array}$ & 1.73 & 3.96 & 3.95 & 9.64 & 0.43 & 4.67 \\
\hline min & 1.84 & 3.57 & 3.80 & 9.21 & & \\
\hline max & 1.73 & 3.65 & 3.87 & 9.47 & 0.26 & 2.82 \\
\hline
\end{tabular}




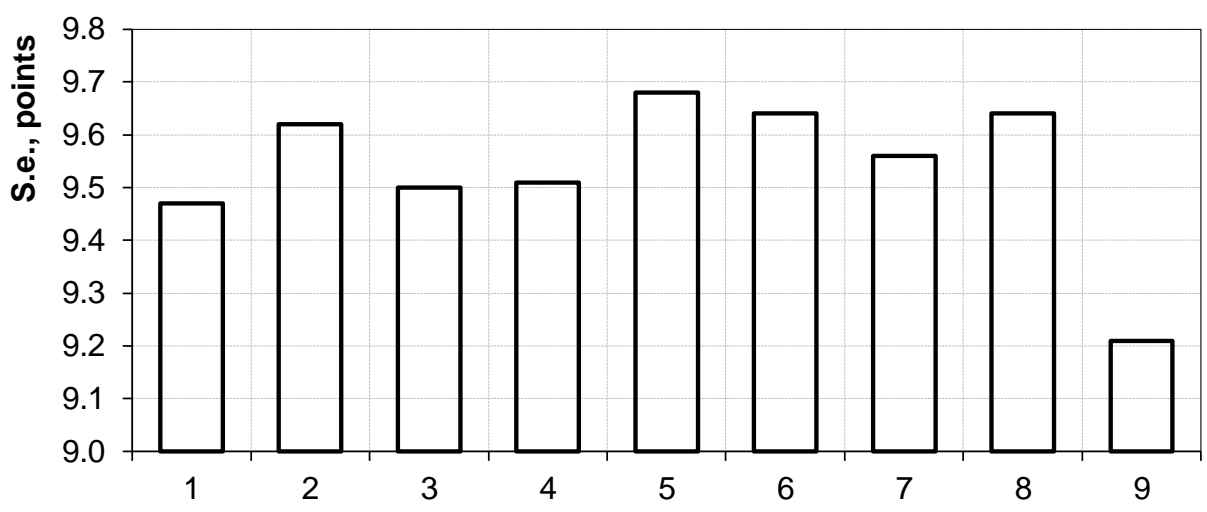

Figure 2. Sensory evaluation $(S . e$. ) indicators of aqueous-alcoholic infusions on the extractant: 1 -Perilla frutescens; 2 - Elsholtzia stauntonii Benth; 3 -Artemisia abrotanum; 4 -Monarda didyma; 5 -Agastache foeniculum; 6 -Satureja hortensis; 7 -Ruta graveolens; 8 - Nepeta transcaucasica Grossch; 9 - aqueous-alcoholic mixture

\section{Antioxidant capacity}

Physicochemical studies, namely determination of the $p H$ level and redox potential, were performed according to the method (Priluckij, 1997) [57] and calculations given above (Kuzmin et al, 2016) [54]. As a result of extraction received infusions (Andreou et al, 2018; Chandrasekara, Shahidi, 2018; Iannitti, Palmieri, 2009; Kawa-Rygielska et al, 2019) [9-12], physicochemical indicators of which are presented in the Table 3 .

Figures 4-7 show graphically the change in the physicochemical indicators of the quality of aqueous-alcoholic infusions of spicy-aromatic raw materials on the extractant.

\section{Quality indicators of aqueous-alcoholic infusions on extractant}

Table 3

\begin{tabular}{|c|c|c|c|c|c|}
\hline Plant raw materials & $\boldsymbol{t}^{\mathbf{}} \mathbf{C}$ & $\boldsymbol{p H}$ & $E h_{\min }, \mathbf{m V}$ & $E h_{\text {cc }}, \mathbf{m V}$ & $R E, \mathbf{~ m V}$ \\
\hline 1. Perilla frutescens & 18 & 7.11 & 233.4 & 124.0 & 109.4 \\
\hline 2. Elsholtzia stauntonii Benth & 19 & 7.04 & 237.6 & 117.0 & 120.6 \\
\hline 3. Artemisia abrotanum & 18 & 7.28 & 223.2 & 103.0 & 120.2 \\
\hline 4. Monarda didyma & 18 & 6.88 & 247.2 & 94.0 & 153.2 \\
\hline 5. Agastache foeniculum & 18 & 6.73 & 256.2 & 120.0 & 136.2 \\
\hline 6. Satureja hortensis & 18 & 7.35 & 219.0 & 108.0 & 111.0 \\
\hline 7. Ruta graveolens & 18 & 6.96 & 242.4 & 141.0 & 101.4 \\
\hline $\begin{array}{c}\text { 8. Nepeta transcaucasica } \\
\text { Grossch }\end{array}$ & 18 & 7.11 & 233.4 & 105.0 & 128.4 \\
\hline 9. Aqueous-alcoholic mixture & 18 & 7.80 & 192.0 & 92.0 & 100.0 \\
\hline min & $\mathbf{1 8}$ & $\mathbf{6 . 7 3}$ & $\mathbf{2 1 9 . 0}$ & $\mathbf{9 4 . 0}$ & $\mathbf{1 0 1 . 4}$ \\
\hline max & $\mathbf{1 9}$ & $\mathbf{7 . 3 5}$ & $\mathbf{2 5 6 . 2}$ & $\mathbf{1 4 1 . 0}$ & $\mathbf{1 5 3 . 2}$ \\
\hline
\end{tabular}

where: $t$ - temperature of infusion; $p H$ - active acidity of the test solution; $E h_{\min }$ - minimal theoretically expected meaning of redox potential; Ehact - actual measured redox potential; $R E$ - recovery energy 

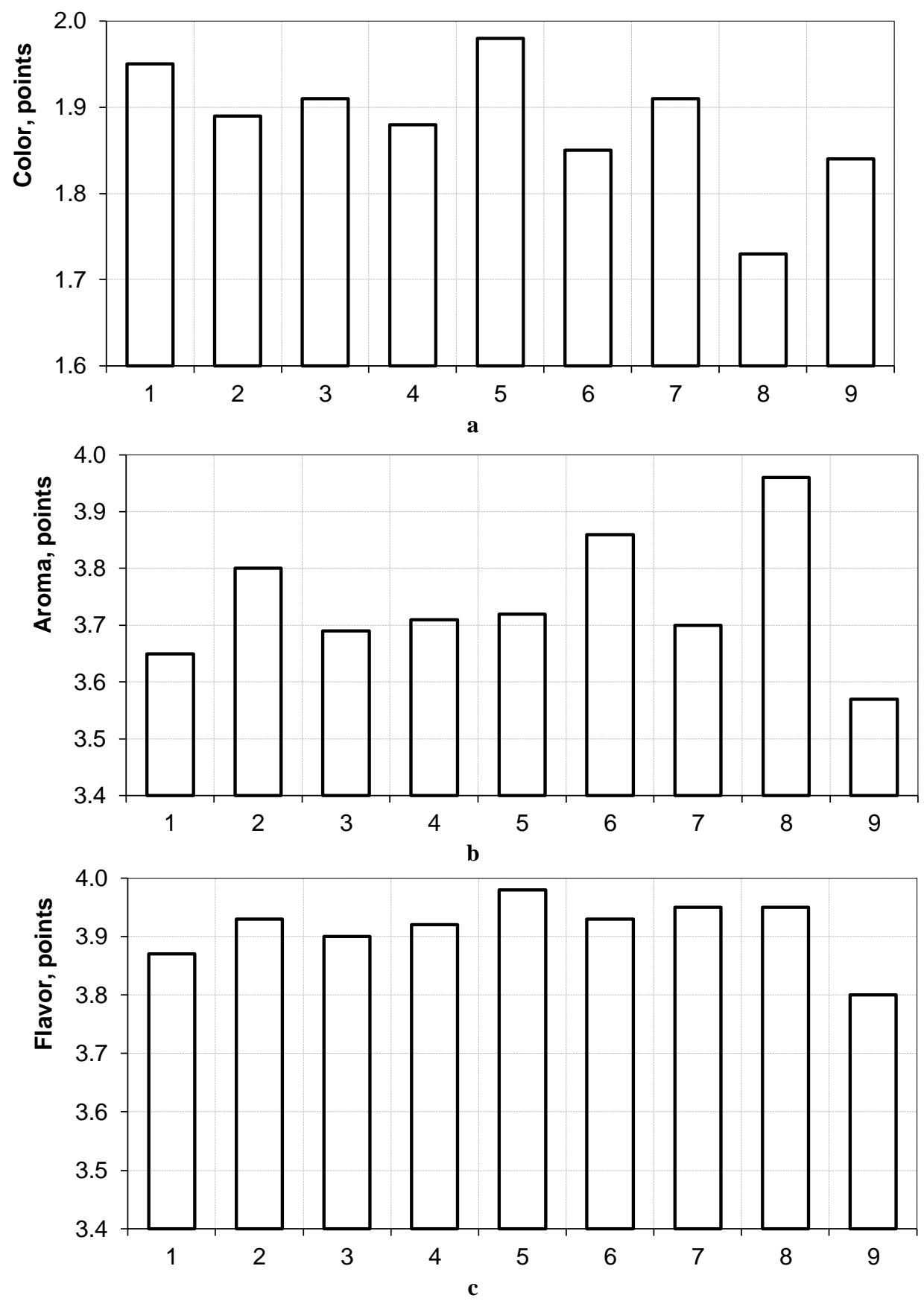

Figure 3. Sensory evaluation indicators of aqueous-alcoholic infusions on extractant: $\mathrm{a}$ - color; $\mathrm{b}$ - aroma; $\mathrm{c}$ - flavor;

1 -Perilla frutescens; 2 - Elsholtzia stauntonii Benth; 3 - Artemisia abrotanum; 4-Monarda didyma; 5 -Agastache foeniculum; 6 - Satureja hortensis; 7 - Ruta graveolens; 


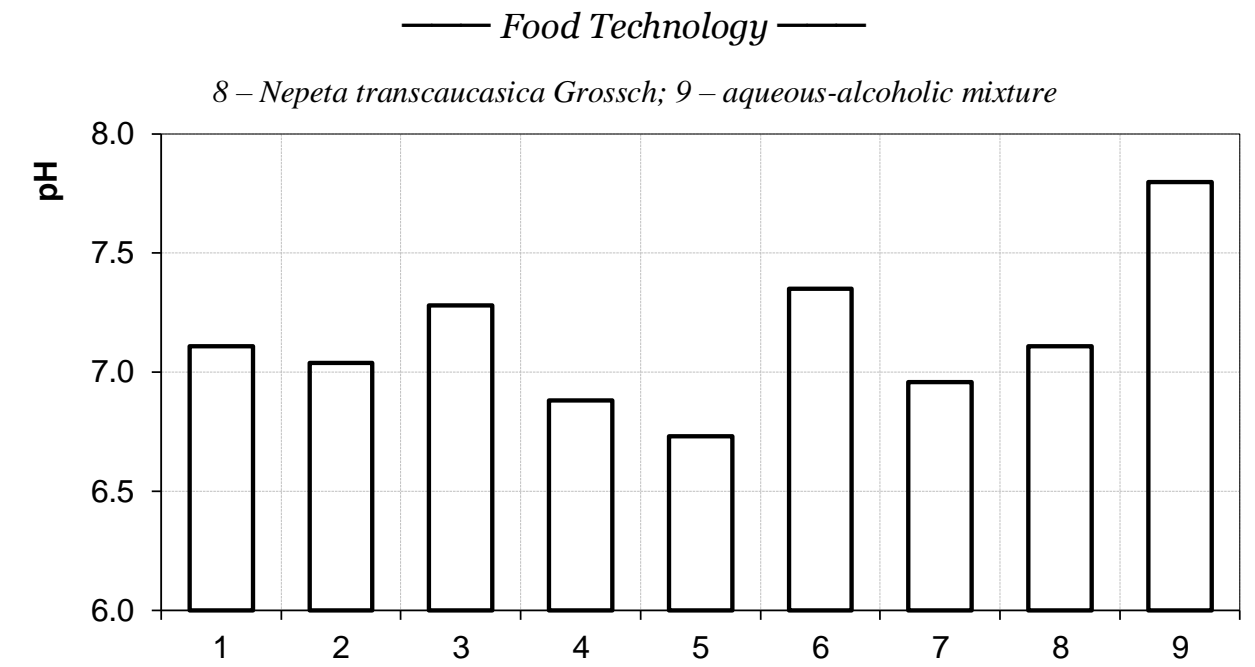

Figure 4. Hydrogen index $(p H)$ of infusions of the investigated raw material:

1 - Perilla frutescens; 2 - Elsholtzia stauntonii Benth; 3 - Artemisia abrotanum; 4 - Monarda didyma; 5 - Agastache foeniculum; 6 - Satureja hortensis; 7 - Ruta graveolens; 8 - Nepeta transcaucasica Grossch; 9 - aqueous-alcoholic mixture

The minimum theoretical value of redox potential $\left(E h_{\min }\right)$ for plant aqueous-alcoholic infusions (Priluckij, 1997) [57] was obtained, which has a value from $219.0 \mathrm{mV}$ (Satureja hortensis) to $256.2 \mathrm{mV}$ (Agastache foeniculum), which is $14.06 \%$ and $33.44 \%$ more than in the control $\left(E h_{\min } 192 \mathrm{mV}\right)$.

The value of the actually measured redox potential for aqueous-alcoholic infusions $E h_{\text {act }}$ from $94.0 \mathrm{mV}$ (Monarda didyma) to $141.0 \mathrm{mV}$ (Ruta graveolens), which is more than $2.17 \%$ and 53.26 $\%$, respectively, for the control $\left(E h_{a c t} 92 \mathrm{mV}\right)$.

In relation to the control (7.80 pH units) infusions have a $p H$ value of 6.73 units $p H$ (Agastache foeniculum) up to 7.35 units $\mathrm{pH}$ (Satureja hortensis), which is $13.72 \%$ and $5.77 \%$, respectively, less than control.

Aqueous-alcoholic infusions from wastes of spicy-aromatic raw materials have a reduction capacity (reduction energy) $R E$ from $101.4 \mathrm{mV}$ (Ruta graveolens) to $153.2 \mathrm{mV}$ (Monarda didyma), which is greater than the control (aqueous-alcoholic mixture) $R E 100 \mathrm{mV}$ by $1.40 \%$ and $53.20 \%$ respectively. Aqueous-alcoholic infusions from waste of spicy-aromatic raw materials have the value of S.e. from 9.47 to 9.68 points in relation to control S.e. 9.21 points. The highest value of S.e. 9.68 points are characteristic of the aqueous-alcoholic infusion of Agastache foeniculum: color - light amber (1.98 points); taste - bright ethereal, herbal, fragrant (3.98 points); aroma - bitter-sour, tart (3.72 points). 


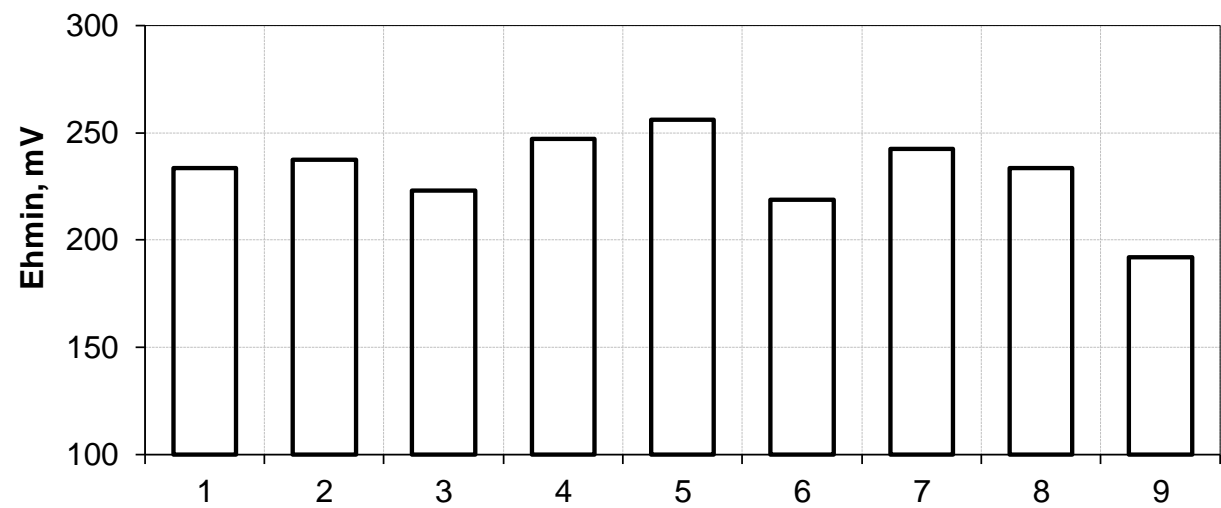

Figure 5. The minimum theoretical value of redox potential $\left(\mathrm{Eh}_{\min }\right)$ of infusions of the investigated raw material

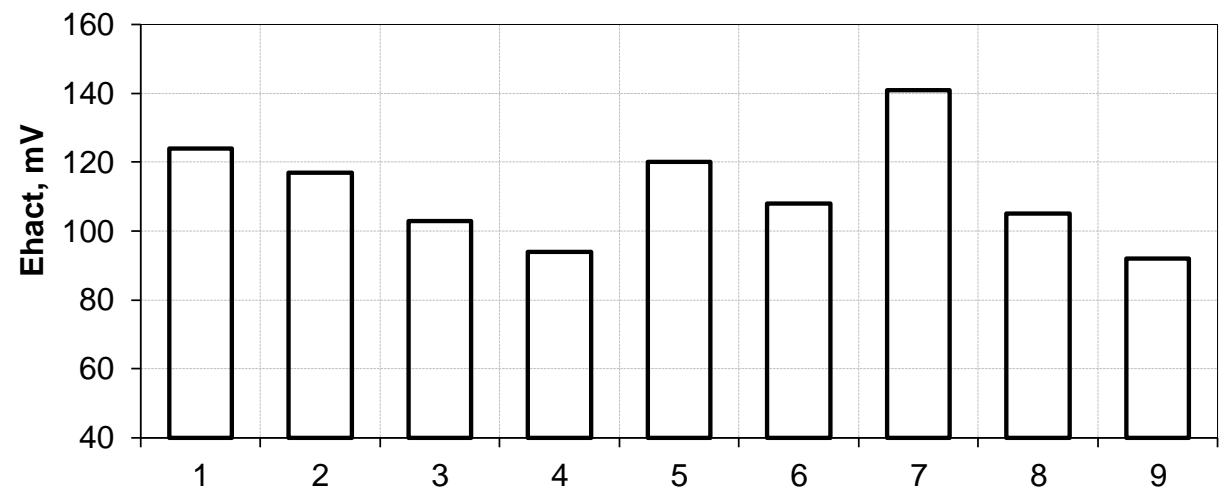

Figure 6. The actual measured redox potential of infusions $\left(\mathrm{Eh}_{\text {act }}\right)$ of infusions of the investigated raw material

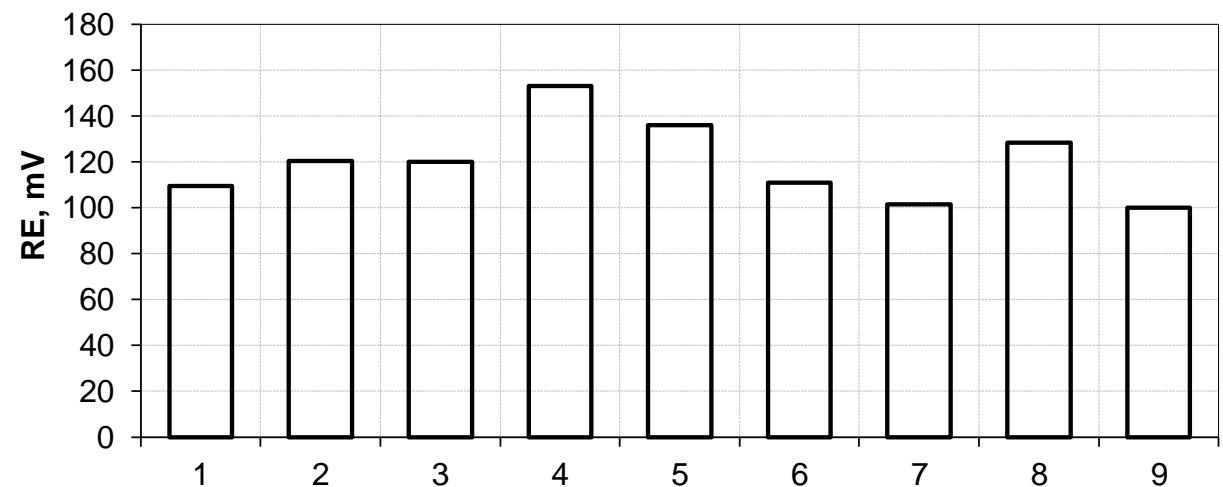

Figure 7. Recovery energy (RE) of infusions of the investigated raw material

For Figures 5-7: 1 - Perilla frutescens; 2 - Elsholtzia stauntonii Benth; 3 - Artemisia abrotanum; 4 - Monarda didyma; 5 - Agastache foeniculum; 6 - Satureja hortensis; 7 - Ruta graveolens; 8 - Nepeta transcaucasica Grossch; 9 - aqueous-alcoholic mixture 


\section{Development of recipes of alcoholic beverages}

On the basis of the obtained results, it was established that the maximum values of redox potential has a aqueous-alcoholic infusion of Ruta graveolens. This aqueous-alcoholic infusion was used in the preparation of cocktail, the recipe of presented in Table 4.

\section{Composition of the cocktail}

Table 4

\begin{tabular}{|c|c|c|c|c|c|c|c|}
\hline \multirow[b]{2}{*}{$\begin{array}{l}\text { № of } \\
\text { point }\end{array}$} & \multicolumn{6}{|c|}{ Content, \% } & \multirow[b]{2}{*}{ Conclusions } \\
\hline & 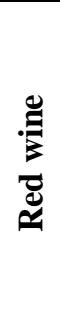 & שֶ & 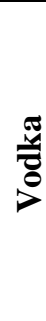 & 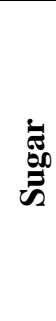 & 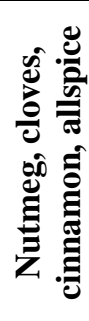 & 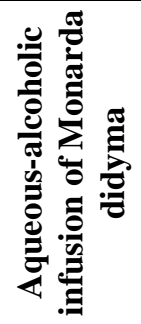 & \\
\hline 1 & 67 & 12 & 7 & 8 & 0.2 & 5.8 & $\begin{array}{l}\text { The composition of the recipe } \\
\text { provides an alcoholic cocktail with } \\
\text { satisfactory physicochemical and } \\
\text { organoleptic characteristics, but } \\
\text { not sufficiently enriched with } \\
\text { biologically active substances }\end{array}$ \\
\hline 2 & 66 & 9 & 5 & 9 & 0.4 & 10.6 & \multirow{3}{*}{$\begin{array}{l}\text { The composition of the recipe } \\
\text { provides an alcoholic cocktail with } \\
\text { good physicochemical and } \\
\text { organoleptic characteristics, and is } \\
\text { also sufficiently enriched with } \\
\text { biologically active substances }\end{array}$} \\
\hline 3 & 64 & 6 & 4 & 10 & 0.6 & 15.4 & \\
\hline 4 & 63 & 3 & 2 & 11 & 0.8 & 20.2 & \\
\hline 5 & 62 & 0 & 0 & 12 & 1.0 & 25.0 & $\begin{array}{l}\text { The composition of the recipe } \\
\text { provides an alcoholic cocktail with } \\
\text { good physicochemical } \\
\text { characteristics and biologically } \\
\text { active substances, but deteriorated } \\
\text { organoleptic characteristics }\end{array}$ \\
\hline
\end{tabular}

The data obtained are correlated with the basic scientific concepts which are displayed in the works (Buglass et al, 2012; Grunert et al, 2018; Gulua et al, 2018) [14-16], regarding the processes of extracting of plant materials.

Improvement of the technology of alcoholic beverages (Andreou et al, 2018; Chandrasekara, Shahidi, 2018; Iannitti, Palmieri, 2009; Kawa-Rygielska et al, 2019; Vergun et al, 2019) [9-13] is due to the addition of spicy-aromatic aqueous-alcoholic infusions. It allows to increase the antioxidant properties of the product (Vergun et al, 2019) [13], will help to increase the immunity of the human body, improve the metabolism, positively affect the cardiovascular system, in addition it increases the consumer properties and will allow to reduce the cost of the finished product. 
The relevance of the use of Monarda didyma in the technology of alcoholic beverages and their waste is confirmed by the studies of other scientists (Wryblewska et al., 2019; Sovova et al., 2015) [35, 36] and our research (Kuzmin et al, 2020) [56].

\section{Conclusions}

1. It is established that one of the promising ways of forming consumer properties and expanding the range of alcoholic products is the use of aqueous-alcoholic infusions from waste of aromatic raw material, which include biologically active substances. Such substances improve the sensory evaluation of beverages, contribute to the promotion of human health (antioxidant effects, enhancing redox reactions).

2. Experimental studies show that all aqueous-alcoholic infusions from waste of aromatic raw materials contain antioxidant systems. It was found that the recovery value of all the tested aqueous-alcoholic infusions is positive and ranges from 101.4 to $153.2 \mathrm{mV}$.

3. Improvement of the technology of alcoholic cocktails by adding spicy-aromatic aqueous-alcoholic infusions allows to increase the redox properties of the product, increases consumer properties and reduces the cost of the finished product.

\section{References}

1. Barik D. (2019), Chapter 3: Energy Extraction From Toxic Waste Originating From Food Processing Industries, Energy from Toxic Organic Waste for Heat and Power Generation, pp. 17-42.

2. Tekler Z.D., Low R., Chung S.Y., Low J.S.C., Blessing L.A. (2019), Waste Management Behavioural Framework of Singapore's Food Manufacturing Industry using Factor Analysis, Procedia CIRP, 80, pp. 578-583.

3. Martin-Rios C., Demen-Meier C., Gössling S., Cornuz C. (2018), Food waste management innovations in the foodservice industry, Waste Management, 79, pp. 196-206.

4. Hall G.M., Howe J. (2012), Energy from waste and the food processing industry, Process Safety and Environmental Protection, 90(3), pp. 203-212.

5. Fujii H., Kondo Y. (2018), Decomposition analysis of food waste management with explicit consideration of priority of alternative management options and its application to the Japanese food industry from 2008 to 2015, Journal of Cleaner Production, 1881, pp. 568574.

6. Galanakis C. (2020), 11: Food waste valorization opportunities for different food industries, The Interaction of Food Industry and Environment, pp. 341-422.

7. Garcia-Garcia G., Stone J., Rahimifard S. (2019), Opportunities for waste valorisation in the food industry - A case study with four UK food manufacturers, Journal of Cleaner Production, 21120, pp. 1339-1356.

8. Mo W.Y., Man Y.B., Wong M.H. (2018), Use of food waste, fish waste and food processing waste for China's aquaculture industry: Needs and challenge, Science of The Total Environment, 613-6141, pp. 635-643.

9. Andreou V., Strati I.F., Fotakis C., Liouni M., Sinanoglou V.J. (2018), Herbal distillates: A new era of grape marc distillates with enriched antioxidant profile, Food Chemistry, 253, pp. $171-178$.

10. Chandrasekara A., Shahidi F. (2018), Herbal beverages: Bioactive compounds and their role in disease risk reduction - A review, Journal of Traditional and Complementary Medicine, 
8(4), pp. 451-458.

11. Iannitti T., Palmieri B. (2009), Antioxidant therapy effectiveness: an up to date, European Review for Medical and Pharmacological Sciences, 13, pp. 245-278.

12. Kawa-Rygielska J., Adamenko K., Kucharska A.Z., Szatkowska K. (2019), Fruit and herbal meads - Chemical composition and antioxidant properties, Food Chemistry, 283, pp. 1927.

13. Vergun O., Svydenko L., Grygorieva O., Shymanska O., Rakhmetov D., Brindza J., Ivanišová E. (2019), Antioxidant capacity of plant raw material of Scutellaria baicalensis Georgi, Potravinarstvo Slovak Journal of Food Science, 13(1), pp. 614-621.

14. Buglass A.J., Caven-Quantrill D.J. (2012), Applications of natural ingredients in alcoholic drinks, Natural Food Additives, Ingredients and Flavourings, 16, pp. 358-416.

15. Grunert K.G., Hieke S., Juhl H.J. (2018), Consumer wants and use of ingredient and nutrition information for alcoholic drinks: A cross-cultural study in six EU countries, Food Quality and Preference, 63, pp. 107-118.

16. Gulua L., Nikolaishvili L., Jgenti M., Turmanidze T., Dzneladze G. (2018), Polyphenol content, anti-lipase and antioxidant activity of teas made in Georgia, Annals of Agrarian Science, 16 (3), pp. 357-361.

17. Ahmed H.M., Tavaszi-Sarosi S. (2019), Identification and quantification of essential oil content and composition, total polyphenols and antioxidant capacity of Perilla frutescens (L.) Britt, Food Chemistry, 2751, pp. 730-738.

18. Lee Y.H., Kim B., Kim S., Kim M.S., Lee J.H. (2017), Characterization of metabolite profiles from the leaves of green perilla (Perilla frutescens) by ultra high performance liquid chromatography coupled with electrospray ionization quadrupole time-of-flight mass spectrometry and screening for their antioxidant properties, Journal of Food and Drug Analysis, 25(4), pp. 776-788.

19. Igarashi M., Miyazaki Y. (2013), A review on bioactivities of perilla: progress in research on the functions of perilla as medicine and food, Evid Based Complement Alternat Med, 2013, pp. 1-7.

20. Yu H., Qiu J.F., Ma L.J., Hu Y.J., Wan J.B. (2017), Phytochemical and phytopharmacological review of Perilla frutescens L. (Labiatae), a traditional ediblemedicinal herb in China, Food and Chemical Toxicology, 108 (B), pp. 375-391.

21. Lee K.N., Shin H.H., Han D.S., Kim Y.O., Choi K.E., Kwag J.S., Back S.H. (1997), Development of anticancer agents from Korean medicinal plants: part 5. Cytotoxic activity of the butanol soluble fraction of Perilla frutescens against human skin melanoma cells, Saengyak Hakhoechi, 28, pp. 264-270.

22. Liu J.H., Steigel A., Reininger E., Bauer R. (2000), Two new prenylated 3-benzoxepin derivatives as cyclooxygenase inhibitors from Perilla frutescens var. acuta, J Nat Prod, 63, pp. 403-405.

23. Banno N., Akihisa T., Tokuda H., Yasukawa K., Higashihara H., Ukiya M., Watanabe K., Kimura Y., Hasegawa J., Nishino H. (2004), Triterpene acids from the leaves of Perilla frutescens and their anti-inflammatory and antitumor-promoting effects, Biosci Biotechnol Biochem, 68, pp. 85-90.

24. Lee J.H., Park K.H., Lee M.H., Kim H.T., Seo W.D., Kim J.Y., Baek I.Y., Jang D.S., Ha T.J. (2013), Identification, characterization, and quantification of phenolic compounds in the antioxidant activity-containing fraction from the seeds of Korean perilla (Perilla frutescens) cultivar, Food Chem, 136 pp. 843-852.

25. Asif M. (2012), Phytochemical study of polyphenols in Perilla frutescens as an antioxidan, Avicenna J Phytomed, 2, pp. 169-178.

26. You C., Wang Y., Zhang W., Yang K., Wu Y., Geng Z., Chen H., Jiang H., Du S., Deng Z., Liu Z. (2014), Chemical constituents and biological activities of the purple perilla essential oil against Lasioderma serricorne, Ind Crop Prod, 61, pp. 331-337. 
27. Guo Z., Liu Z., Wang X., Liu W., Jiang R., Cheng R., She G. (2012), Elsholtzia: phytochemistry and biological activities, Chemistry Central Journal, 6(1), 1-8.

28. Wu Z.Y., Li X.W., Huang S.R. (1977), Flora reipublicae popularis sinicae, Beijing: Science press, 66, 304-348.

29. Afshar F.H., Delazar A., Nazemiyeh H., Nahar L., Moghaddam S.B., Mbaebie B.O., Gibbons S., Sarker S.D. (2017), Melilotoside derivatives from Artemisia splendens (Asteraceae), Records of Natural Products, 11(1), pp. 43-50.

30. Bora K.S., Sharma A. (2011), The genus Artemisia: a comprehensive review, Pharmaceutical Biology, 49(1), pp. 101-109.

31. Tan R.X., Zheng W., Tang H. (1998), Biologically active substances from the genus Artemisia, Planta Medica, 64 pp. 295-302.

32. Taleghani A., Emami S.A., Tayarani-Najaran Z. (2020), Artemisia: a promising plant for the treatment of cancer, Bioorganic \& Medicinal Chemistry, 28(1), 115180.

33. Muangphrom P., Misaki M., Suzuki M., Shimomura M., Muranaka T. (2019), Identification and characterization of (+)- $\alpha$-bisabolol and 7-epi-silphiperfol-5-ene synthases from Artemisia abrotanum, Phytochemistry, 164, pp. 144-153.

34. Amirmohammadi M., Khajoenia S., Bahmani M., Rafieian-Kopaei M., Qorbani M. (2014), In vivo evaluation of antiparasitic effects of Artemisia abrotanum and Salvia officinalis extracts on Syphacia obvelata, Aspiculoris tetrapetra and Hymenolepis nana parasites, Asian Pacific Journal of Tropical Disease, 4(1), pp. 250-254.

35. Wryblewska K., Szumny A., Ïarowska B., Kromer K., Fabian S. (2019), Impact of mulching on growth essential oil composition and its biological activity in Monarda didyma L., Industrial Crops and Products, 129, pp. 299-308.

36. Sovova H., Sajfrtova M., Topiar M. (2015), Supercritical $\mathrm{CO}_{2}$ extraction of volatile thymoquinone from Monarda didyma and M. fistulosa herbs, The Journal of Supercritical Fluids, 105, pp. 29-34.

37. Hashemi M., Ehsani A., Hassani A., Afshari A., Aminzare M., Sahranavard T., Azimzadeh Z. (2017), Phytochemical, antibacterial, antifungal and antioxidant properties of Agastache foeniculum essential oil, Journal of Chemical Health Risks, 7(2), 95-104.

38. Shtereva L., Vassilevska-Ivanova R., Stancheva I., Geneva M., Stoyanova E. (2016), Evaluation of antioxidant activity of Agastache foeniculum and Agastache rugosa extracts, Comptes rendus de l'Acadümie bulgare des Sciences, 69(3), pp. 295-302.

39. Park W.T., Kim H.H., Chae S.C., Cho J.W., Park S.U. (2014), Phenylpropanoids in Agastache foeniculum and Its Cultivar A. foeniculum 'Golden Jubilee', Asian Journal of Chemistry, 26(15), pp. 4599-4601.

40. Deans S.G., Svoboda K.P. (1989), Antibacterial activity of summer savory (Satureja hortensis L.) essential oil and its constituents, Journal of Horticulturel Science, 64, pp. 205 210.

41. Hajhashemi V., Sadraei H., Ghannadi A.R., Mohseni M. (2000), Antispasmodic and antidiarrhoel effect of Satureja hortensis L. essential oil, Journal of Ethnopharmacology, 71, pp. 187-192.

42. Leung A.Y., Foster S. (1996). Encyclopaedia of Common Natural Ingredients used in Foods, Drugs, and Cosmetics, 2nd ed. Wiley, New York, pp. 465-466.

43. Madsen H.L., Andersen L., Christiansen L., Brockhoff P., Bertelsen G. (1996), Antioxidative activity of summer savory (Satureja hortensis L.) and rosemary (Rosmarinus officinalis L.) in minced, cooked pork meat, Zeitschrift fur Lebensmittel-Untersuchung undForschung, 203, pp. 333-338.

44. Boroja T., Katanić J., Rosić G., Selaković D., Joksimović J., Mišić D., Stanković V., Jovičić N., Mihailović V. (2018), Summer savory (Satureja hortensis L.) extract: Phytochemical profile and modulation of cisplatin-induced liver, renal and testicular toxicity, Food and Chemical Toxicology, 118, pp. 252-263. 
45. Colucci-D’Amato L., Cimaglia G. (2020), Ruta graveolens as a potential source of neuroactive compounds to promote and restore neural functions, Journal of Traditional and Complementary Medicine, 10(3), pp. 309-314.

46. Ahmed O.M., Moneim A.A., Yazid I.A., Mahmoud A.M. (2010), Antihyperglycemic, antihyperlipidemic and antioxidant effects and the probable mechanisms of action of Ruta graveolens infusion and rutin in nicotinamide-streptozotocin-induced diabetic rats, Diabetologia croatica, 39(1), pp. 15-35.

47. Khouri N.A., El-Akawi Z. (2005), Antiandrogenic activity of Ruta graveolens L in male Albino rats with emphasis on sexual and aggressive behavior, Neuroendocrinology letters, 26(6), pp. 823-829.

48. Tabanca N., Demirci B., Kiyan H.T., Ali A., Bernier U.R., Wedge D.E., Khan I., Bacer K.H.C. (2012), Repellent and larvicidal activity of Ruta graveolens essential oil and its major individual constituents against Aedes aegypti, Planta Medica, 1, pp. 78-90.

49. Ratheesh M., Helen A. (2013). Oral administration of alkaloid fraction from Ruta graveolens inhibits oxidative stress and inflammation in hypercholesterolemic rabbits. Pharmaceutical Biology, 51(12), pp. 1552-1558.

50. Attia E.Z., Abd El-Baky R.M., Desoukey S.Y., Mohamed M.A.E.H., Bishr M.M., Kamel M.S. (2018), Chemical composition and antimicrobial activities of essential oils of Ruta graveolens plants treated with salicylic acid under drought stress conditions, Future Journal of Pharmaceutical Sciences, 4(2), 254-264.

51. Stashenko E.E., Acosta R., Martınez J.R. (2000), High-resolution gas-chromatographic analysis of the secondary metabolites obtained by subcritical-fluid extraction from Colombian rue (Ruta graveolens L.), Journal of Biochemical and Biophysical Methods, 43(1-3), pp. 379-390.

52. Salehi B., Valussi M., Jugran A.K., Martorell M., Ramirez-Alarcon K., Stojanovic-Radic Z.Z., Antolak H., Kregiel D., Mileski K.S., Sharifi-Rad M., Setzer W.N., Cadiz-Gurrea M.L., Segura-Carretero A., Sener B., Sharifi-Rad J. (2018), Nepeta species: From farm to food applications and phytotherapy, Trends in food science \& technology, 80, pp. 104-122.

53. Rakhmetov D.B. (2011), Teoretychni ta prykladni aspekty introduktsiyi roslyn v Ukrayini, Kiev: Ahrar Media Crup.

54. Kuzmin O., Kovalchuk Y., Velychko V., Romanchenko N. (2016), Improvement technologies of aqueous-alcoholic infusions for the production of syrups, Ukrainian Journal of Food Science, 4(2). pp. 258-275.

55. Kuzmin O., Levkun K., Riznyk A. (2017), Qualimetric assessment of diets, Ukrainian Food Journal, 6(1), pp. 46-60.

56. Kuzmin O., Kucherenko V., Sylka I., Isaienko V., Furmanova Y., Pavliuchenko E., Hubenia V. (2020), Antioxidant capacity of alcoholic beverages based on infusions from nontraditional spicy-aromatic vegetable raw materials, Ukrainian Food Journal, 9(2), 404-424.

57. Priluckij V.I. (1997), Okislitel'no-vosstanovitel'nyj potencial dlja harakteristiki protivokislitel'noj aktivnosti razlichnyh napitkov $i$ vitaminnyh komponentov, Jelektrohim. aktivacija v medicine, sel. hozjajstve, prom-sti: I Mezhdunar. Simpozium.

58. Frolova N., Ukrainets A., Sylka I., Nemirich A., Kuzmin O. (2019), Separation of terpenes from lemon essential oil by selective fractionation under a vacuum, Eastern-European Journal of Enterprise Technologies, 2/11 (98), pp. 32-36.

59. Kuzmin O. (2017), Mechanism of transformation of protons in the process of creating aqueous-alcoholic mixtures, Ukrainian Food Journal, 6(4), pp. 686-697. 